\title{
Qualidade Percebida e seus Impactos sobre a Sa- tisfação, Confiança e Lealdade: um estudo com varejistas eletrônicos de serviços de download gratuito
}

\author{
Paulo de Paula Baptista \\ Wesley Vieira da Silva ${ }^{2}$ \\ Lirian Patty Goss ${ }^{3}$
}

\section{Resumo}

Este trabalho tem como objetivo avaliar a opinião dos consumidores quanto à qualidade dos serviços oferecidos por sites de download gratuitos na internet $e$ verificar qual a influência na lealdade, satisfação e confiança para com os sites. A amostra final coletada constitui-se de 5.793 usuários que utilizam sites de download. Como técnicas de análise dos dados utilizaram-se as estatísticas univariadas convencionais e a técnica de modelagem de equações estruturais. Os resultados auferidos confirmam trêsdas seishipóteses estabelecidas, a priori, demonstrando que a satisfação possui efeitos diretos e positivos sobre a lealdade e a confiança; e a qualidade percebida possui efeitos diretos sobre a satisfação, já quetrês outras hipóteses foram rejeitadas, indicando que nem a qualidade $e$ nem a confiança possuem efeitos diretos sobre a lealdade e que a qualidade também não influencia diretamente a confiança.

Palavras-chave: Qualidade percebida. Satisfação. Lealdade. Confiança. Sites de download.

\footnotetext{
${ }^{1}$ Professor do Programa de Pós-Graduação em Administração da Pontifícia Universidade Católica do Paraná - PUC/PR. End.: R. Imaculada Conceição, 1155, Bl. Acadêmico, Mestrado/Doutorado em Administração, Bairro Prado Velho, Curitiba - PR. CEP: 80.215-901 - Brasil. E-mail: p.baptista@pucpr.br.

${ }^{2}$ Professor do Programa de Pós-Graduação em Administração da Pontifícia Universidade Católica do Paraná - PUC/PR. End.: R. Imaculada Conceição, 1155, Bl. Acadêmico, Mestrado/Doutorado em Administração, Bairro Prado Velho, Curitiba-PR. CEP: 80.215-901 -Brasil. E-mail: wesley.vieira@pucpr.br.

${ }^{3}$ Especialista em Marketing pela Pontifícia Universidade Católica do Paraná - PUC/PRe especialista em MBA - Gestão de negócios pela Universidade Positivo. End.: R. Imaculada Conceição, 1155, Bl. Acadêmico, Mestrado/Doutorado em Administração, Bairro Prado Velho, Curitiba - PR. CEP: 80.215-901 - Brasil.E-mail: lirianpatty@yahoo.com.br.

Artigo recebido em: 25/09/2010. Aceito em: 25/07/2011. Membro do Corpo Editorial Científico responsável pelo processo editorial: Emerson Antônio Maccari.

(c) (i) (9) Esta obra está sob uma Licença Creative Commons Atribuição-Uso.
} 


\section{Introdução}

O avanço e o rápido desenvolvimento do comércio eletrônico têm ampliado o interesse dos pesquisadores de marketing por temas relacionados a esse segmento. Dentre vários outros aspectos, destaca-se a busca de um melhor entendimento do comportamento do consumidor na internet $e$ dos processos pelos quais os clientes se mantêm ou não leais a uma determinada empresa no ambiente eletrônico.

A internet é um importante foco de estudo e atenção para os profissionais de marketing, havendo um enorme interesse em se compreender que efeitos os ambientes mediados por computadores exercem no comportamento (HOFFMAN; NOVAK, 1996; DEGERATU; RANGASWAMY, 2000; BAPTISTA, 2005; BREI, 2001; BREI; ROSSI, 2002; ROSA, 2001).

A facilidade de acesso aos computadores, a redução dos seus custos para aquisições, o surgimento de novos equipamentos de informática (os Handhelds, computadores pessoais e os celulares) $e$ as diferentes formas de acesso à internet disponibilizadas no mercado, hoje, popularizam e difundem cada vez mais o download de programas pela internet, concretizando a inserção de empresas especializadas no oferecimento deste serviço.

Dholakia e Bagozzi (1999) afirmam que a criação de um ambiente online agradável para os consumidores possui resultados positivos no comércio eletrônico na internet, desenvolvendo uma vantagem competitiva para as empresas inseridas neste segmento.

Empresas que adotam o marketing orientado para seus consumidores constantemente preocupam-se com sua satisfação, que também se destaca em pesquisas relacionadas ao comportamento do consumidor. Garbarino e Johnson (1999) alegam que a satisfação, durante décadas, foi apontada como principal previsora do comportamento pós-compra.

O Marketing Science Institute (MSI) classificou o gerenciamento dos consumidores como o terceiro tópico mais importante no ranking de prioridades de suas pesquisas para o triênio de 2002-2004; sendo a retenção dos consumidores, o gerenciamento da lealdade à marca e aos canais de marketing e a avaliação da lealdade seus principais subtópicos, justificandose, assim, a relevância do tema escolhido para este estudo.

Reforçando a importância de estudos que abordam a lealdade dos consumidores e alguns de seus antecedentes, destaca-se a afirmação de Gommanset al. (2001, p. 43), para quem "Construir e manter a lealdade à 
marca tem sido um tema central da teoria e prática de marketing no estabelecimento de vantagens competitivas sustentáveis".

Estudos de vários autores (BREI, 2001; HERNANDEZ, 2002; HERNANDEZ, 2003; LAGES; BRASIL, 2000; GONÇALVES FILHO et al., 1998; AMARAL; NIQUE, 2000; COSTA; LARAN 2003; COSTA, 2003; VIEIRA et al., 1998) procuram compreender o perfil e o comportamento de compra e não compra dos consumidores na internet, as avaliações de confiança, a satisfação e a qualidade percebida.

Apesar do interesse despertado pelo estudo do comportamento dos consumidores no comércio eletrônico, observa-se, ainda, a existência de baixo volume de estudos brasileiros no que se refere à mensuração da lealdade e seus antecedentes no contexto eletrônico de downloads. Os estudos existentes nessa área estão concentrados nos segmentos bancários (NEZZE, 2002; BREI; ROSSI, 2002; ROSA; KAMAKURA, 2002; COSTA FILHO, 2002; ROSA, 2001; ROSA; MAZZON, 2002) ou de varejo virtual de produtos de consumo (BAPTISTA, 2005).

A carência de estudos e informações sobre a lealdade do consumidor em ambiente eletrônico virtual relacionado a serviços de download direciona a definição do seguinte problema de pesquisa: Qual a relação entre a qualidade percebida pelos consumidores no uso de sites de serviços de download gratuitos de programas na internet $e$ a satisfação, a confiança e a lealdade apresentados para com estes sites?

Em decorrência ao problema de pesquisa mencionado, o presente estudo tem como objetivo geral avaliar qual a opinião dos consumidores quanto à qualidade dos serviços oferecidos por sites de download gratuitos na internet e verificar qual a sua influência na lealdade, na satisfação e na confiança para com o site.

O trabalho encontra-se estruturado em cinco seções que podem ser sumarizadas como segue: a primeira traz a parte introdutória; a segunda trata da revisão teórico-empírica; a terceira refere-se à metodologia utilizada na pesquisa, bem como as sua limitações; a quarta traz a apresentação e a análise dos dados e a quinta enfoca as conclusões e recomendações para trabalhos futuros. 


\section{Referencial Teórico-Empírico}

Para Solomon (2002), a compra é uma resposta a um problema ou uma necessidade percebida. Nesse processo de compra, o estudo do comportamento do consumidor avalia de que modo ocorre a decisão do consumidor e como ele irá gastar seus recursos de tempo, dinheiro e esforço no consumo de produtos (SCHIFFMAN; KANUK, 2000). Engel, Blackwell eMiniard (2000) complementam que o comportamento do consumidor estuda as atividades envolvidas no processo de obtenção e de consumo, incluindo o processo de decisão que precede e sucede essas atividades e costuma ser classificado nos estágios: reconhecimento do problema, busca de informações, avaliação de alternativas, compra, consumo e avaliação pós-consumo.

Considerando a delimitação do problema deste estudo, é dada maior ênfase aos conceitos diretamente relacionados com as avaliações e comportamentos posteriores à compra, tais como qualidade percebida, satisfação, confiança e lealdade.

\subsection{Qualidade Percebida}

Grönroos (1995) e Fornell (1991) consideram a definição mais importante de qualidade como a definição sob a ótica do cliente. Sendo assim, qualidade é a conformação às especificações do cliente e o que conta é o que o cliente percebe como qualidade. Kotler (2000) descreve que são os atributos e características dos produtos ou serviços que satisfazem às necessidades declaradas ou implícitas dos consumidores.

Para Anderson e Fornell (1994), a qualidade pode ser vista como um potencial intrínseco aos atributos do produto ou serviço de prover satisfação, ressaltando que a qualidade percebida depende da função de utilidade para o cliente em relação ao nível de qualidade ou desempenho fornecido. $\mathrm{Na}$ definição de Aaker (1998), qualidade percebida é um sentimento amplo e intangível a respeito da marca, não estando associada ao conhecimento de especificações técnicas ou de análises profundas e criteriosas de características do produto. $\mathrm{O}$ autor considera ainda, que a percepção de qualidade influencia diretamente a decisão de escolha e lealdade à marca. 
Barcellos (2002) cita o modelo P/E (Percepções e Expectativa), no qual as percepções dos clientes são comparadas com suas expectativas, demonstrando que o importante é o que o cliente percebe como qualidade. Para Prado (2002), a qualidade percebida tem sido definida, também, como uma relação entre as expectativas comparativamente à performancepercebida de um serviço.

Parasuraman et al. (1985) propuseram o modelo SERVQUAL, uma estrutura mais conhecida e amplamente aplicada, em que a qualidade percebida é mensurada pela diferença entre os escores atribuídos ao desempenho percebido e à expectativa de desempenho. Quanto mais positivo for o resultado, maior é o nível de qualidade; quanto mais negativo for o resultado, pior é a avaliação dos consumidores.

Nesse sentido, Oliver (1997) não avalia isoladamente a expectativa e o desempenho, considerando apenas a avaliação subjetiva da Desconformidade. Para operacionalização da mensuração desta desconformidade, Marchetti e Prado (2001) utilizam-se de uma escala do tipo "Muito melhor do que o esperado" até "Muito pior do que o esperado", proporcionando a vantagem de o consumidor realizar o processo comparativo internamente, aplicando a escala uma vez somente, não sendo necessário aplicar primeiramente para as expectativas e após para o desempenho.

O modelo SERVQUAL utiliza cinco diferentes dimensões da qualidade percebida: confiabilidade, responsividade, segurança, empatia e tangibilidade. Essas dimensões representam, respectivamente, consistência no desempenho; atender às necessidades do consumidor conforme sua percepção; a confiança no serviço e sua credibilidade; o comprometimento da empresa com o serviço; e a aparência das evidências físicas, instalações e equipamentos (ZEITHAML; BITNER, 2003).

Carman (1990) discutiu a estabilidade do modelo SERVQUAL, sugerindo que, para avaliações específicas, faz-se necessário considerar a particularidade a cada caso, customizando os itens utilizados para mensuração da qualidade.

Para Cronin e Taylor (apud BAPTISTA, 2005), as medidas baseadas unicamente no desempenho são as melhores para utilizar na avaliação da qualidade do serviço, reduzindo consideravelmente o número de itens a serem medidos quando comparado ao modelo SERVQUAL. Realizaram um estudo em quatro diferentes segmentos de serviços, no qual uma comparação entre escala ponderada e não ponderada foi realizada. Nos quatro ca- 
sos, a utilização da mensuração não ponderada explicou a maior parcela da variação na medida global de qualidade de serviço.

De modo geral, a qualidade percebida pelo consumidor é um fator considerado crucial para a construção e manutenção de vantagens competitivas (SOLOMON, 2002).

\subsection{Satisfação}

A satisfação do consumidor é considerada um dos pilares dos conceitos de marketing. Sua importância explica-se pelos reflexos provocados na retenção de clientes (ROSA; KAMAKURA, 2002), fator que apresenta melhor relação custo-benefício para as empresas do que a aquisição de novos clientes (REICHHELD, 2000).

Para Abreu (1996), o pós-marketing tem como objetivo manter os clientes satisfeitos após a compra, aumentar a recompra de clientes atuais, reconhecê-los como indivíduos e mantê-los conscientes de que estão sendo cuidados.

Cardozo (1965) foi pioneiro nos estudos de satisfação do consumidor como uma resposta pós-compra descrevendo que "[...] a satisfação do consumidor com um produto leva à repetição de compra, aceitação de outros produtos na mesma linha de produto, bem como ao boca-a-boca favorável" (CARDOZO, 1965, p. 244).

Anderson, Fornell e Lehmann . (1992) e Johnson e Fornell (1991) definem a satisfação como uma avaliação global de um consumo a longo prazo com diversas experiências de compra.

As diferenças na abordagem utilizada para definição da satisfação são amplamente explicadas por autores como Prado (2004), Rosa (2001), Marchetti e Prado (2001), Garbarino e Johnson (1999), Fornel et al. (1996), Anderson et al. (1994) e Rossi e Slongo (1997) que ressaltam a diferença existente entre a satisfação cumulativa ou total e a satisfação pontual ou específica.

A satisfação cumulativa ou total é "[...] uma avaliação global baseada na experiência total de compra e consumo de um bem ou serviço ao longo do tempo" (ANDERSON et al., 1994, p. 54).

Para Rossi e Slongo (1997), a satisfação específica ou pontual pode ser medida através da avaliação do consumidor em uma experiência única de 
consumo de um produto ou serviço. Já Garbarino e Johnson (1999) a descrevem como restrita a uma determinada transação, um julgamento pós-compra imediato ou ainda uma reação efetiva para a mais recente experiência de compra.

Os estudos de Bolton e Drew (1991), Oliver e Desarbo (1988), Tse e Wilton (1988), Churchil e Surprenant (1982), Oliver (1981), Andreansen e Lindestad (1998) e Oliver (1999) apontam relações diretas da satisfação com as expectativas e a performance.

Marchetti e Prado (2001) afirmam em seu estudo que a avaliação da satisfação pode ser realizada por meio da utilização de diversos métodos. Os métodos mais difundidos são aqueles originados no paradigma de desconformidade, que se baseia na divergência percebida entre o desempenho e o padrão de referência.

A compra e o uso subsequente revelam os níveis de desempenho reais, que são comparados aos níveis de expectativa pelo uso de parâmetros do tipo "melhor do que" ou "pior do que o esperado", com base na experiência própria dos consumidores. O julgamento que resulta dessa comparação é rotulado de desconfirmação, que pode ser negativa se o produto for percebido como pior do que o esperado; desconfirmação positiva, se percebido como melhor do que o esperado; ou simples confirmação ou desconfirmação zero, se ocorre o esperado (OLIVER, 1980).

Outro método de mensuração muito utilizado é o ACSI (American Customer Satisfaction Index ou Índice de satisfação do cliente norte-americano). Ele incorpora, além da medida de lealdade, a qualidade percebida, o valor percebido, a satisfação global e as reclamações. Corresponde a uma medição de resultados baseada no mercado, que propõem avaliar empresas, indústrias, setores econômicos e economias nacionais (FORNEL et al., 1996).

\subsection{Confiança}

Não somente a área de marketing, como outras áreas afins, apresentam contribuições importantes para o estudo da confiança, permitindo, assim, melhorar a compreensão das relações existentes entre as organizações, seus membros e clientes (BAPTISTA, 2005).

Segundo Bitner (1995), a confiança, sob o ponto de vista do cliente, é um relacionamento constituído a cada encontro com a empresa, especialmente em se tratando de serviços. 
Para Santos (2000), em relacionamentos contínuos entre consumidores e empresas, a confiança é associada a fatores como: consistência, competência, honestidade, responsabilidade e cooperação entre as partes.

Rousseau et al. (1998), além de Brei e Rossi (2002), define confiança como um estado psicológico do consumidor, em que o mesmo aceita e compreende a vulnerabilidade nas expectativas positivas sobre as intenções e comportamento do outro, baseada na crença de que ele agirá de maneira íntegra e responsável.

Para Rotter (1967, p. 651), confiança é "[...] uma expectativa mantida por um indivíduo ou grupo de que se pode contar com a palavra, promessa, declaração verbal ou escrita de outro indivíduo ou grupo".

Autores como Nooteboom, Berger e Noorderhaven(1997), Berry (1995) e Rossi e Santos (2002) têm enfatizado o papel crucial do construto confiança em promover a lealdade em trocas mais relacionais.

[...] a inerente natureza dos serviços, juntamente com a abundante desconfiança da América, posiciona a confiança como talvez a ferramenta mais poderosa do marketing de relacionamento disponível para uma empresa (BERRY, 1995, p. 42).

Reichheld e Schefter (2000, p. 176) afirmam que "[...] o fator mais importante para a escolha de um provedor de serviços no mundo virtual é a confiança”.

McKnight et al. (2002) apresentam um modelo interativo entre os quatro diferentes tipos de confiança que consideram principais dentre os diferentes tipos de confiança identificados na literatura que compõem os comportamentos relacionados à confiança: disposição para confiar, confiança institucional, crenças de confiança e intenções de confiança.

Em face de dificuldade de se trabalhar com todas essas dimensões em conjunto com os construtos Qualidade Percebida, Satisfação e Lealdade, a presente pesquisa operacionaliza apenas as crenças de confiança.

\subsection{Lealdade do Consumidor}

Um dos conceitos mais discutidos na área de marketing nos anos de 1990 foi "marketing de relacionamento". Esse conceito é baseado na ideia 
de se desenvolver relacionamentos duradouros entre empresas e consumidores, ao invés de realizar troca discretas, que têm "[...] começo distinto, curta duração e exato final após a performance" (DWYER; SCHURR, 1987, p. 13).

A filosofia do gerenciamento de relações tem destacado a importância do conceito de lealdade, tornando-o elemento chave para o desenvolvimento de trocas relacionais. Dessa maneira, estudos que investiguem os processos e mecanismos que influenciam na lealdade do consumidor têm tido grande repercussão na área de marketing (DICK; BASU, 1994; OLIVER, 1999; BAPTISTA, 2005, URBAN et al., 2000; PRADO 2002).

De maneira geral, clientes leais podem elevar o crescimento dos rendimentos de uma empresa, pois eles são mais inclinados a fazer compras adicionais de produtos e serviços e geram novos negócios para a empresa por meio da propaganda bocaaboca (BERRY; PARASURAMAN, 1991; ZEITHAML; BITNER, 2000 apud BAPTISTA, 2005).

Oliver (1999) descreve a lealdade como a existência de um comprometimento profundo em comprar ou utilizar novamente um produto ou serviço no futuro e, assim, promover compras repetidas da mesma marca ou de um grupo de produtos da mesma marca e da mesma empresa, apesar de influências situacionais e esforços de marketing terem o potencial de causar comportamento de mudança. A essa definição, o autor chamou de "Lealdade Última" (Ultimate Loyalty), sugerindo que ela é formada a partir de um conjunto de satisfações e de experiências positivas continuamente recebidas do fornecedor.

Dick e Basu (1994) elaboraram um modelo considerando aspectos atitudinais da lealdade. No modelo, os autores consideram que a lealdade possui três categorias de antecedentes: os Antecedentes Cognitivos, os Antecedentes Afetivos e os Antecedentes Conativos.

Chaudhuri e Holbrook (2001) ressaltam a existência de duas abordagens de lealdade: a Lealdade Atitudinal, considerada para este estudo, e a Lealdade Comportamental. A Lealdade Atitudinal inclui o comprometimento predisposto em termos de algum valor único associado a uma marca ou fornecedor. Mensura lealdade pela preferência, intenção de recompra e boca a boca. Já a Lealdade Comportamental refere-se ao comportamento continuado e repetido de compra, ou à predisposição em fazê-lo e mensura lealdade pela taxa de recompra. 


\section{Metodologia da Pesquisa}

No decorrer da revisão teórico-empírica desta pesquisa, pode-se observar um número considerável de estudos que abordam a relação entre a lealdade e seus antecedentes e também constata-se um número pequeno de trabalhos estruturados com modelos que avaliam os antecedentes da lealdade em ambientes exclusivos da internet, principalmente no que se refere aos sites de download gratuito.

O modelo proposto neste estudo tem como objetivo demonstrar as relações diretas e indiretas existentes entre a lealdade, satisfação, qualidade percebida e confiança dos usuários de Internet para com os sites de download gratuitos.

No intuito de responder ao problema de pesquisa formulado para o trabalho e tendo como base o referencial teórico apresentado, a investigação apontou para as seguintes hipóteses:

Anderson e Fornell (1994), afirmam que a qualidade é um potencial intrínseco aos atributos do produto ou serviço de prover satisfação. Considerando tal afirmação, desenvolveu-se a Hipótese $\mathrm{H} 1$ :

\section{H1: Quanto maior a qualidade percebida do site de download gratuito, maior a satisfação com relação a ele.}

Aaker (1998) define que a qualidade percebida é um sentimento amplo e intangível a respeito da marca, e considera que a percepção de qualidade influencia diretamente a decisão de escolha e lealdade à marca. A partir dessa definição foi proposta mais uma hipótese, a H2:

\section{H2: Quanto maior a qualidade percebida pelo site de download gratuito, maior a lealdade em relação a ele.}

Para Baptista (2005), quando um cliente percebe que recebe serviços ou produtos com alta qualidade, a empresa fornecedora espera que ele a reconheça como detentora de habilidades necessárias para apresentar bom desempenho. A percepção do consumidor de que a empresa customiza a oferta para cada cliente, pode levá-lo a interpretar que a empresa se preocupa com seus clientes. Estes dois aspectos retratam uma relação entre a qualidade e as dimensões competência e benevolência subjacentes ao construto confiança. Considerando tal afirmação, desenvolveu-se a Hipótese H3: 
H3: Quanto maior a qualidade percebida do site de download gratuito, maior a confiança depositada no site.

Autores como Nooteboom, Berger e Noorderhaven(1997), Berry (1995) e Ganesan (1994) têm enfatizado o papel crucial do construto confiança em promover a lealdade nas trocas relacionais. Para eles os sentimentos de confiança garantem que a performance da empresa é consistente e competente, indicando que o consumidor permanecerá obtendo valor em suas recompras, reduzindo-se o risco nas trocas relacionais. Nesse caso, a confiança contribui para dar continuidade à relação e cria sentimentos de lealdade. A Hipótese H4 considera a afirmação dos autores:

H4: Quanto maior a confiança no site de download gratuito, maior a lealdade para com o site.

O processo de avaliação de satisfação do consumidor continua após a compra e o consumo do produto, e pode resultar em satisfação ou em insatisfação. O resultado sendo satisfação leva o consumidor à repetição da compra e aceitação de outros produtos da mesma linha de produtos (CARDOZO, 1965). A Hipótese H5 deriva dessa informação.

\section{H5: Quanto maior a satisfação com o site de download gra- tuito, maior a lealdade para com o site.}

Para Lau e Lee (apud BAPTISTA, 2005), a explicação da associação direta entre satisfação e confiança reside no fato de que, em relacionamentos contínuos, a satisfação cumulativa eleva a percepção do cliente sobre a benevolência e credibilidade da empresa, duas importantes dimensões da confiança. A partir dessa constatação, propõe-se a última hipótese deste trabalho H6:

H6: Quanto maior a satisfação com o site de download gratuito, maior a confiança depositada no site.

Com base nas hipóteses deste estudo, apresenta-se o modelo estrutural da pesquisa na Figura 1. 


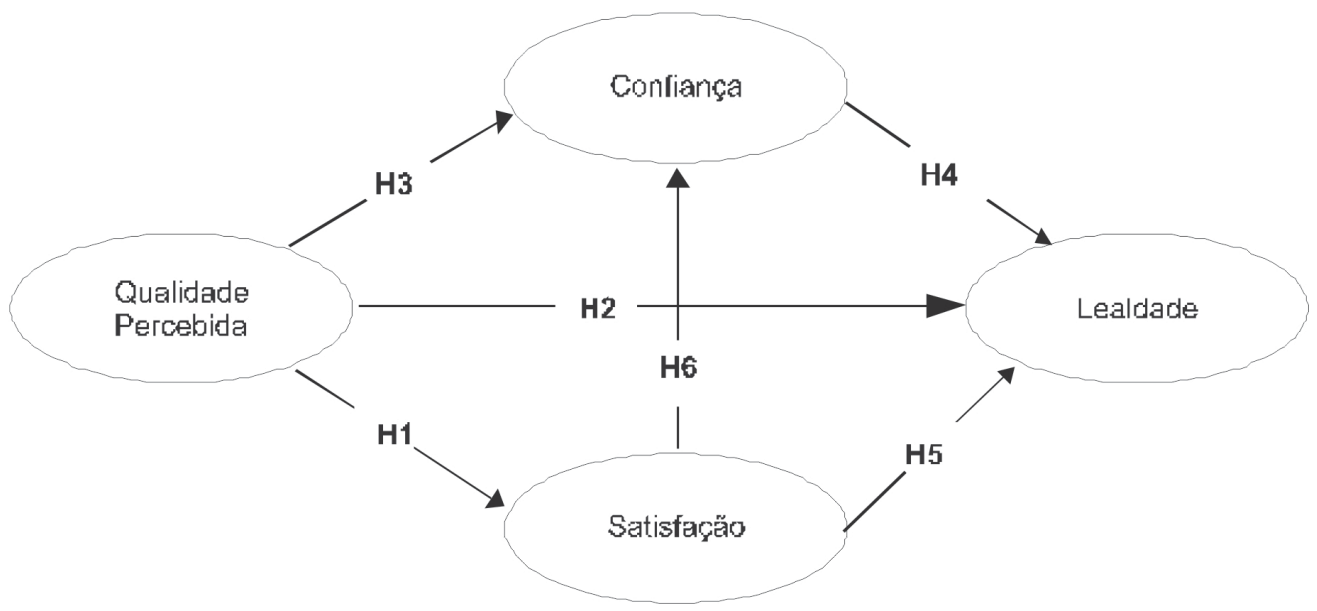

Figura 1: Modelo Estrutural da Pesquisa

Fonte: Elaborada pelos autores

\subsection{Delineamento da Pesquisa}

Inicialmente desenvolveu-se uma pesquisa qualitativa com característica exploratória, utilizando o método Focus Group, a fim de identificar, junto aos usuários de sites de download gratuito, quais são os atributos mais importantes relacionados aos serviços oferecidos pelos sites conhecidos e utilizados.

O levantamento efetuado por meio do Focus Group foi realizado em dezembro de 2005 com um grupo de nove usuários de site de download gratuito na internet e teve por finalidade a identificação das variáveis utilizadas na composição da escala de avaliação da qualidade percebida, incorporada posteriormente no instrumento de coleta de dados deste estudo.

Após a fase exploratória utilizada para a construção do instrumento de coleta de dados, o presente estudo assumiu a configuração de uma pesquisa quantitativa descritiva com corte transversal único de análise.

\subsection{População e Amostragem}

A população é o universo para o qual os pesquisadores generalizam os resultados encontrados, sendo delimitada, neste trabalho, como os indivíduos residentes no Brasil, usuários de sites de download gratuitos na internet $e$ 
que tenham efetuado download de algum serviço ofertado pelo site Zamunga nos últimos dois meses. Ressalta-se que o nome fictício de Zamunga para o site estudado foi adotado em razão da não autorização para a divulgação de seu nome verdadeiro.

A unidade amostral para este trabalho é o indivíduo usuário de internet, residente no Brasil que efetuou nos últimos dois meses pelo menos um download no site de download gratuito na internet, Zamunga. O tipo de amostra utilizado foi o não probabilístico por adesão.

\subsection{Coleta de Dados}

Para este trabalho foram utilizadas como fonte de dados secundários: materiais publicados em periódicos acadêmicos, livros, monografias, dissertações de mestrado e teses de doutorado. Já a coleta de dados primários ocorreu por meio de um instrumento de coleta de dados disponibilizado diretamente na internet abrangendo questões para identificação do perfil dos entrevistados, hábitos de utilização da internet e serviços de download e questões que identificam as variáveis de lealdade, confiança, qualidade percebida e satisfação.

O instrumento de coleta de dados, questionário, foi submetido a um pré-teste com 25 entrevistados, para verificar a facilidade de compreensão e de preenchimento das respostas. Não havendo dificuldade para o preenchimento e compreensão do questionário, finalizou-se a construção do mesmo adaptando-o para publicação em uma página de internet.

$\mathrm{Na}$ etapa definitiva de coleta de dados, o questionário foi disponibilizado na internet para preenchimento através do siteZamunga, no período de $1^{\circ}$ a 4 de junho de 2006. Objetivando um alto fluxo de adesão ao preenchimento do questionário, foi enviado um convite aos 90 mil usuários cadastrados no site, juntamente com o informativo eletrônico do site, que é enviado quinzenalmente para os usuários que se cadastraram solicitando e autorizando o seu recebimento.

Durante o preenchimento do questionário, as respostas dos entrevistados foram gravadas em um banco de dados elaborado utilizando a linguagem de programação SQL, sem fazer necessária sua digitação. Ao fim do período de coleta, as informações gravadas no banco de dados foram exportadas para a planilha eletrônica Microsoft ${ }^{\circledast}$ Excel e submetido ao processo de crítica e codificação das respostas. 


\subsection{Operacionalização dos Construtos}

O construto qualidade percebida foi operacionalizado a partir de escalas de desempenho de dez pontos para avaliação do site de download gratuito quanto à conexão, navegabilidade e informação. Os itens foram adaptados de modelos encontrados em estudos anteriores e destacados na Revisão Literária, considerando-se também os julgamentos dos usuários de sites de download gratuito na internet obtidos durante a entrevista de focusgroup.

Para a mensuração dos construtos Confiança, Satisfação e Lealdade foram utilizadas escalas bietápicas de seis pontos, na qual as variações ocorriam da Concordância (totalmente, muito e pouco) a discordância (pouco, muito e totalmente).

Para uma primeira avaliação crítica dos construtos qualidade e lealdade foram efetuadas Análises Fatoriais Exploratórias (EFA), que ajudaram a definir as dimensões para cada um dos construtos e excluir algumas questões para melhor adequação a mensuração. Os construtos satisfação e confiança foram trabalhados como variáveis latentes de primeira ordem não sendo submetidos à EFA.

\subsection{Tratamento dos Dados}

Durante o processo de crítica, verificou-se que $28,1 \%$ dos entrevistados abandonaram o preenchimento do questionário antes de finalizá-lo. Dentre os 6.011 questionários preenchidos até a finalização, 196 entrevistados não realizaram pelo menos um download nos últimos dois meses no site Zamunga e 22 não responderam a essa questão, totalizando 218 questionários.

Obteve-se um resultado de 5.793 questionários válidos para análise e tratamento dos dados que foram exportados da planilha eletrônica Microsoft ${ }^{\circledR}$ Excel para o programa Statistical Package for the Social Sciences (SPSS ${ }^{\circledR}$ ) versão 13.0 e AMOS $^{\circledR}$ versão 5.0.

Utilizou-se de técnicas estatísticas univariadas e multivariadas, obtidas por meio dos softwares Statistical Package for the Social Sciences 13.0 e $\mathrm{AMOS}^{\circledR} 5.0$, para análise dos dados desta pesquisa.

$\mathrm{Na}$ amostra final procedeu-se a análise das frequências nas questões relacionadas ao perfil sociodemográfico, perfil dos usuários de site de 
download, Tipos de uso da internet e Padrão de utilização dos serviços de download.

Após a caracterização do perfil da amostra, utilizou-se da técnica de modelagem de equações estruturais $(\mathrm{SEM})^{4}$ para mensuração dos construtos, satisfação, qualidade percebida, confiança e lealdade, bem como suas relações, abordados neste estudo.

A técnica SEM, é uma modelagem de diversas técnicas multivariadas que examina uma série de relações de dependência simultaneamente (HAIR Jr. et al., 2005).

As relações nesta abordagem são definidas por uma série de equações que descrevem as estruturas hipotetizadas das relações. A força e a convicção que um pesquisador pode assumir a causalidade entre duas variáveis baseiam-se na justificativa teórica que apoia as análises (HAIR Jr. et al., 2005).

Essas relações costumam ser representadas na forma de um diagrama. O diagrama pode ser entendido como um grupo de afirmativas que resumem um conjunto de hipóteses (HAIR Jr. et al., 2005). O diagrama apresentado na Figura 2 resume o conjunto de relações testadas neste estudo.

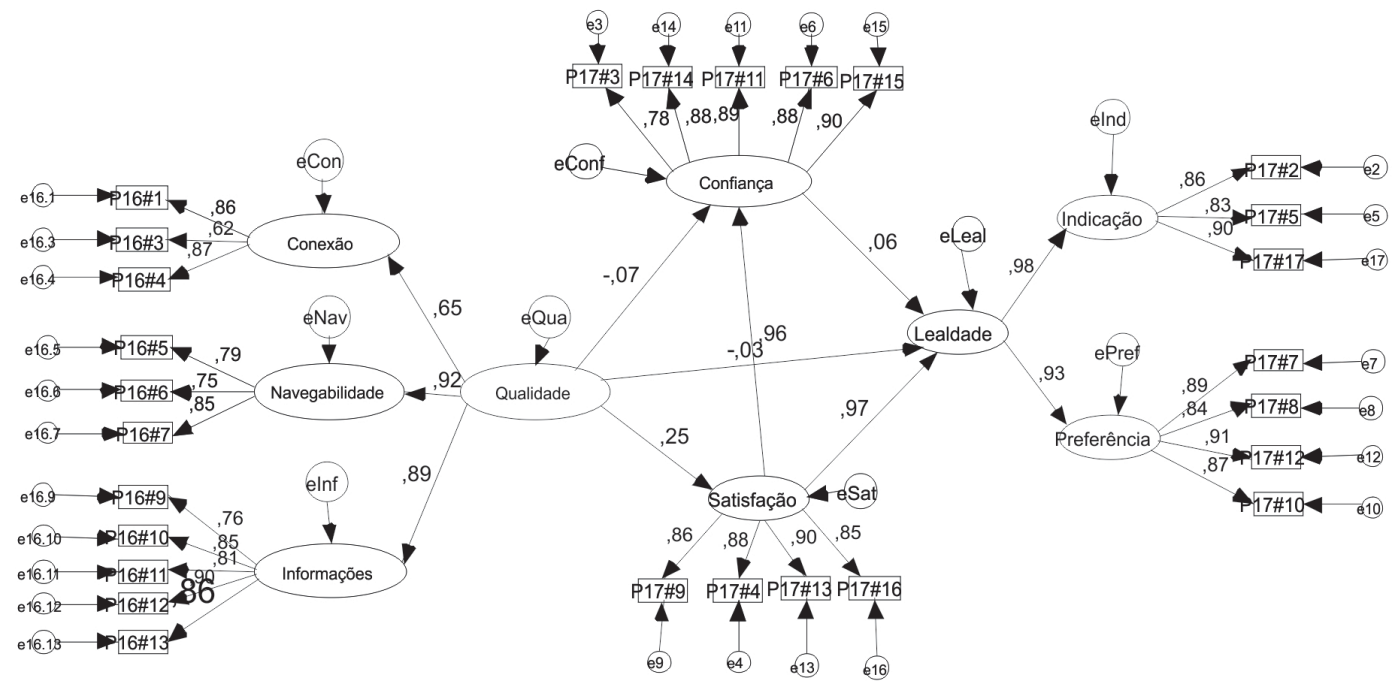

Figura 2: Diagrama de Caminhos do Modelo Teórico

Fonte: Elaborada pelos autores 


\subsection{Limitações da Pesquisa}

Com o intuito de manter-se transparente na contribuição oferecida por este estudo, listam-se a seguir as limitações identificadas para o método utilizado na coleta e análise de dados.

A abordagem de corte transversal único, adotada neste trabalho, não permite a identificação de mudanças de comportamento que poderiam ocorrer em longo prazo e não é a mais indicada para medir relações de causa e efeito entre as variáveis, para tal finalidade, são mais adequados estudos experimentais, entretanto, tais estudos demandam mais tempo para a coleta de dados e manipulação das variáveis estudadas. Busca-se minimizar os efeitos dessa limitação por meio dos estudos de hipóteses fundamentadas na revisão da literatura e teorias dominantes na área de comportamento do consumidor.

Outra limitação apresentada refere-se ao procedimento amostral utilizado. A amostragem nãoprobabilística faz com que as inferências estatísticas fiquem limitadas ao grupo de entrevistados. É importante considerar também que a pesquisa limita-se apenas ao grupo de usuários de um site de download gratuito disponível na internet, mesmo sendo um dos sites com maiores índices de utilização e acessos do Brasil não se pode generalizar as análises e resultados para os demais grupos que utilizam e acessam os demais sites na internet.

Por fim, na mensuração dos antecedentes da lealdade, não foram incorporados ao estudo as variáveis valor e comprometimento. Sugere-se, portanto, que futuros estudos incorporem tais variáveis no modelo do estudo $e$ mensuração dos antecedentes de lealdade dos usuários de sites de download gratuito na internet.

\section{Apresentação e Análise dos Resultados}

No perfil dos usuários de site de download, verifica-se uma predominância de usuários do sexo masculino, sendo 82,9\% e uma heterogeneidade entre as idades a partir de 16 anos. Caracteriza-se por forte presença de usuários com o colegial completo/Superior incompleto com mais da metade dos usuários.

Considerando há quanto tempo os usuários utilizam a internet, 48,3\% dos entrevistados conhecem e utilizam a internet há mais de seis anos, sendo 
um percentual significativo se for considerado que se iniciou a utilização da internet há pouco mais de 11 anos no Brasil. Mais de 89,8\% dos usuários de site de download gratuito possuem conexão de internet em sua residência e $52,6 \%$ acessam a internet em seu trabalho.

Quando questionados sobre os sites que mais gostam, os usuários de sites de download gratuito demonstram preferência por sites de download 87,3\%; sites de notícias 65\%; sites de música $62,4 \%$ e sites de humor $51,3 \%$.

Percebe-se que as compras efetuadas pela internet não se configuram como um processo novo para os usuários de sites de download gratuito, pois $70,2 \%$ dos entrevistados já efetuaram compras pela internet. Quanto à utilização da internet, identifica-se que mais da metade dos entrevistados utilizam a internet para entretenimento e mais de $1 / 4$, a utiliza para trabalho.

Observa-se neste estudo uma heterogeneidade na quantidade de horas diárias que os entrevistados utilizam a internet. Isso demonstra ser a utilização de download um recurso que não se restringe apenas aos heavy users da internet.

Identifica-se, também, que fazerdownload pela internet não é um procedimento novo para a maioria dos entrevistados, sendo que $84,4 \%$ realizaram seu primeiro downloadhá mais de um ano, sendo que $1 / 3$ dos entrevistados afirmam ter realizado dez ou mais downloads no site Zamunga nos últimos dois meses, o que comprova um alto índice de utilização do site. Os downloads com maiores apontamentos de realizações foram o de programas e softwares com $91,9 \%$, seguido por músicas com $81,4 \%$ e Papel de parede com $78,7 \%$.

Com relação aos conhecimentos dos usuários quanto à utilização do computador e da internet, comprova-se que $87,8 \%$ dos entrevistados sabem instalar e desinstalar programas, fator importante para a utilização de sites de download gratuito.

Para avaliação do modelo estrutural da satisfação, qualidade percebida, confiança e lealdade, utiliza-se a técnica SEM, mantendo as estruturas de variáveis latentes obtidas nos modelos de mensuração dos construtos.

A especificação de um modelo em SEM envolve a explicitação de declarações sobre um conjunto de parâmetros que indicam as relações entre cada um dos pares de variáveis que compõem esse modelo. Esses parâmetros podem ser definidos como fixos ou livres. Os parâmetros fixos não são estimados pelos dados coletados, sendo-lhes normalmente atribuído o valor zero. 
Já os parâmetros livres são aqueles que o pesquisador deseja estimar por acreditar que são significativamente diferentes de zero (HOYLE, 1995).

Os métodos de estimação mais conhecidos em SEM são o ML, Máxima Verossimilhança; o GLS, Mínimos Quadrados Generalizados; o WLS, Mínimos Quadrados Ponderados; e o ADF, Assintoticamente Livre de Distribuição (HAIR Jr. et al., 2005).

Dentre esses métodos citados, o ML é o mais frequentemente utilizado por ser eficiente e não viesado, quando a suposição de normalidade multivariada é atendida (HOYLE, 1995).

Considerando as observações expostas e a necessidade de avaliar um modelo estrutural com mais de 5.500 casos, em que se constatou ausência de normalidade multivariada, aplicou-se o procedimento de estimação ML com o emprego de bootstrapping.

O bootstrapping é um método que calcula estimativas de parâmetros e seus intervalos de confiança repetida vezes, utilizando-se de um subconjunto aleatório da amostra de dados original, com base em múltiplas estimações (HAIR Jr. et al., 2005).

Foram utilizadas três medidas de ajustamento absoluto: o $\chi^{2} / \mathrm{gl}$, Quiquadrado sobre graus de liberdade; o GFI, Índice de Qualidade do Ajuste; e a RMSEA, Raiz do Erro Quadrático Médio. E quatro medidas para ajustamento incremental: CFI, Índice de Ajuste Comparativo; NFI, Índice de Ajuste Normado; IFI, Índice de Ajuste Incremental e TLI, Índice de Tucker-Lewis.

A Tabela 1 apresenta o resumo dos valores obtidos para as medidas de ajustamentos do modelo estrutural. Com exceção da razão do $\chi^{2} / \mathrm{gl}=19,51$ que é muito sensível ao tamanho da amostra, todos os demais valores de ajustamento demonstram ser estatisticamente adequados. 
Tabela 1: Medidas de Ajustamento do Modelo Estrutural

\begin{tabular}{|c|c|}
\hline \multicolumn{1}{|c|}{ Índices } & Modelo estrutural \\
\hline Medidas de Ajustamento Absoluto & \\
\hline$\chi^{2} / \mathrm{gl}$ - Qui-quadrado sobre graus de liberdade & 19,51 \\
\hline GFI - Índice de Qualidade do Ajuste & 0,922 \\
\hline RMSEA - Raiz do Erro Quadrático Médio de Aproximação & 0,057 \\
\hline Medidas de Ajustamento Incremental & \\
\hline CFI - Índice de ajuste comparativo & 0,961 \\
\hline NFI - Índice de ajuste normado & 0,959 \\
\hline IFI - Índice de ajuste incremental & 0,961 \\
\hline TLI - Índice Tucker-Lewis & 0,956 \\
\hline
\end{tabular}

Fonte: Elaborada pelos autores

Nas medidas de ajustamento absoluto, o GFI manteve-se acima do limite mínimo de 0,9 e o indicador RMSEA mantêm-se um pouco acima do limite mínimo de 0,05 e abaixo do limite máximo de 0,8.

Nas medidas de ajustamento incremental, tanto o CFI, quanto o NFI, o IFI e o TLI mantiveram-se acima do valor 0,9 preconizado pela literatura sobre Modelagem de Equações Estruturais.

Analisando esses resultados, julgou-se adequada à estrutura de relações proposta no modelo estrutural deste estudo. Para avaliação das hipóteses são consideradas as magnitudes e significâncias estatísticas dos coeficientes de regressão padronizados estimados para o modelo, apresentados na Tabela 2. 
Tabela 2: Resumo dos Testes de Hipóteses

\begin{tabular}{|ccc|c|c|c|}
\hline \multicolumn{2}{|c|}{ Relação Estrutural } & Coeficiente Padronizado & Hipótese & Status \\
\hline Qualidade $\rightarrow$ & Satisfação & $0,247^{* *}$ & $\mathrm{H} 1$ & Verificada \\
\hline Qualidade $\rightarrow$ & Lealdade & $-0,031$ n.s. & $\mathrm{H} 2$ & Rejeitada \\
\hline Qualidade $\rightarrow$ & Confiança & $-0,067$ n.s. & H3 & Rejeitada \\
\hline Confiança $\rightarrow$ & Lealdade & 0,058 n.s. & H4 & Rejeitada \\
\hline Satisfação $\rightarrow$ & Lealdade & $0,965^{* *}$ & H5 & Verificada \\
\hline Satisfação $\rightarrow$ & Confiança & $0,956^{* *}$ & H6 & Verificada \\
\hline
\end{tabular}

n.s. Resultados não significativos

* Resultados significativos a $<<0.01$

Fonte: Elaborada pelos autores

Em relação ao papel desempenhado pela qualidade percebida no contexto deste trabalho, predomina o conceito de que ela representa um antecedente direto da satisfação, assim possui apenas impacto indireto na lealdade (MARCHETTI; PRADO, 2001; FORNELL et al., 1996; BAPTISTA, 2005).

Nos estudos de Baptista (2005) e Prado (2004), a percepção de qualidade contribui para o aumento da confiança para com o fornecedor, construindo-se numa relação positiva e direta entre as duas variáveis.

Quanto a essas perspectivas, a hipótese "H1: Quanto maior a qualidade percebida do site de download gratuito, maior a satisfação com relação a ele" foi verificada. Já as hipóteses "H2: Quanto maior a qualidade percebida pelo site de download gratuito, maior a lealdade em relação a ele" e "H3: Quanto maior a qualidade percebida do site de download gratuito, maior a confiança depositada no site" foram rejeitadas.

Para a hipótese H3, acredita-se que a rejeição originou-se por tratar-se de uma compra sem a existência de um pagamento ou repasse de informações sigilosas, o que pode ter diminuído o risco percebido pelo consumidor, reduzindo assim a importância da qualidade como antecedente da confiança.

Evidências empíricas e formulações teóricas apontam a relação da confiança como antecedente da lealdade (BREI, 2001; PRADO, 2004). Para Baptista (2005), essa relação não se comprovou no contexto do varejo eletrônico.

Nesse sentido, a hipótese "H4: Quanto maior a confiança no site de download gratuito, maior a lealdade para com o site" foi também rejeitada. 
Proposições sobre a ocorrência de relações diretas da satisfação como antecedente do desenvolvimento da confiança e da lealdade são comumente apresentadas por estudos já referenciados (PRADO, 2004; MARCHETTI; PRADO, 2001; ROSSI; SANTOS, 2002; GARBARINO; JOHNSON, 1999; FORNELL et al., 1996).

Reforçando tais proposições, foram verificadas as hipóteses "H5: Quanto maior a satisfação com o site de download gratuito, maior a lealdade para com o site" e "H6: Quanto maior a satisfação pelo site de download gratuito, maior a confiança depositada no site".

A Figura 3 demonstra o resumo das relações estruturais obtidos do modelo, destacando os coeficientes padronizados dos caminhos que indicam a intensidade da associação direta entre os construtos. Indicando as relações significativas, com linhas contínuas e não significativas, com linhas tracejadas.

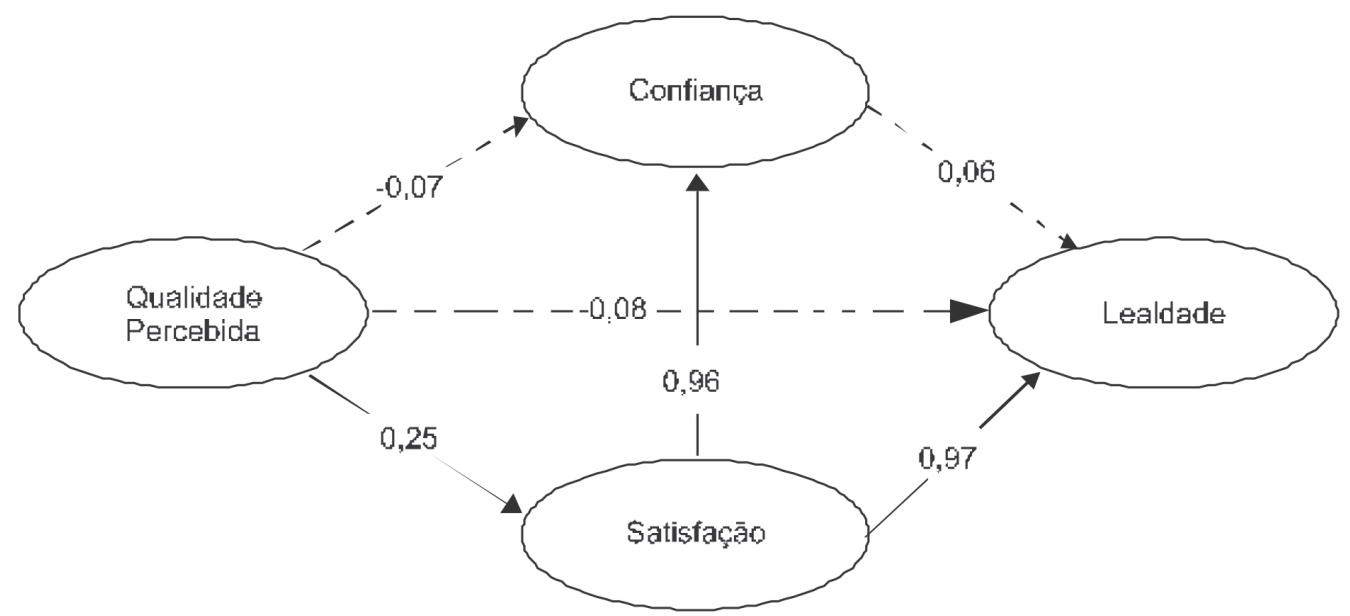

Figura 3: Modelo Estrutural e os Coeficientes de Determinação Fonte: Elaborada pelos autores

Para todos os construtos analisados neste trabalho, pode-se considerar o construto satisfação com o resultado mais satisfatório. Logo, mantém-se como o construto com maior impacto direto sobre os demais. Com efeitos diretos significativos com a lealdade $(0,965)$ e a confiança $(0,956)$.

Já o construto qualidade percebida não apresenta efeito direto significativo sobre a lealdade $(-0,031)$ e a confiança $(-0,067)$, e o construto confiança não apresenta efeito significativo sobre a lealdade $(0,058)$. 


\section{Conclusões e Recomendações}

O objetivo principal deste estudo, conforme destacado no problema de pesquisa foi a proposição e teste do modelo integrado dos construtos qualidade percebida, satisfação, confiança e lealdade.

O modelo proposto apresentou adequadas medidas de ajustamento, com exceção do $\chi^{2} / \mathrm{gl}$ que foi muito sensível a amostras maiores. Os resultados confirmaram três das seis hipóteses a priori estabelecidas, demonstrando que a Satisfação possui efeitos diretos e positivos sobre a Lealdade e a Confiança; e que a Qualidade Percebida possui efeitos diretos e positivos sobre a Satisfação. As três hipóteses rejeitadas indicaram que nem Qualidade e nem Confiança possuem efeitos diretos sobre a Lealdade e que a Qualidade também não possui efeitos diretos sobre a confiança.

Despertou especial atenção a não verificação de relações significativas entre a Qualidade Percebida e a Confiança, pois ela é amplamente proposta por pesquisas que abordam estes dois construtos. Uma justificativa encontrada para a ocorrência deste evento seria a ausência de pagamentos pelos serviços e, portanto, menor percepção de risco pelos usuários de sites de download gratuito.

Este estudo avaliou o consumo de serviços oferecidos por sites de download gratuitos, caracterizados por breves contatos com a empresa e nenhuma interação com funcionários de fronteira. Tais características também poderiam representar uma plausível explicação para a ausência de relação entre a Confiança e a Lealdade e Qualidade e a Confiança.

Perante o caráter mais transacional que parece dominar o segmento analisado, os sites de download gratuitos devem redobrar esforços na manutenção dos elevados índices de satisfação de seus usuários.

Sugere-se, por fim,que novos estudos sejam aplicados também a usuários de outros sites de download gratuito, para avaliar se a estrutura de relações dos antecedentes da lealdade também se repete em outras empresas que não possuam a elevada notoriedade do Zamunga, um dos lideres no segmento estudado $e$, que, portanto, goza de grande credibilidade entre os entrevistados, o que pode ter afetado também as associações entre confiança e outros construtos. 


\section{Perceived Quality and it's Impacts on Satifaction, Trust and Loyalty: a study in eletronic retailers of free download services}

\section{Abstract}

This work aims at evaluating the opinion of the consumers about the quality of the services offered by toll-free download websites and at assessing the corresponding influence in terms of loyalty, satisfaction and trust toward the sites. The final sample collected consists of 5.793 users who use download websites. To analyze the data, conventional techniques of univariated statistics and the technique of modeling of structural equations were used. The results thus obtained have confirmed three of the six hypotheses that had been defined a priori, demonstrating that satisfaction has direct and positive effects on loyalty and trust and that perceived quality has direct effects on satisfaction. Three other hypotheses have been rejected, indicating that neither quality nor trust have direct effects on loyalty and that quality also does not directly influence trust.

Key words: Perceived quality. Satisfaction.Loyalty. Trust. Download websites.

\section{Referências}

AAKER, D A. Marcas: Brand equit - gerenciando o valor da marca. São Paulo: Negócio Editora, 1998.

ABREU, C. B. Serviço pós-venda: a dimensão esquecida do marketing. Revista de Administração de Empresas, São Paulo, v. 36, n. 3, p. 24-31, 1996.

AMARAL, B. L.; NIQUE, W. M. E-commerce: atributos determinantes na utilização da Internet como canal de compra. In: Anais eletrônico do $2^{\circ}$ Encontro Anual da ANPAD, Campinas, Marketing, 2000, p.152-153.

ANDERSON, E. W. et al. Customer satisfaction, market share and profitability. Journal of Marketing, v. 58, p. 53-66, 1994.

ANDERSON, E. W.; FORNELL, C. A customer satisfaction research prospectus.Service Quality: new direction in theory and practice. Thousand Oaks, Sage publications, 1994. 
ANDERSON, E. W.; FORNELL, C.; LEHMANN, D. R. Perceived quality, customer satisfaction, market share and profitability. Working Paper, NQRC (National Quality Research Center): The University of Michigan, 1992.

ANDREANSEN E. W.; LINDESTAD, B. Customer loyalty and complex services: the impact of corporete image on quality, customer satisfaction and loyalty for costumers with varying degrees of service expertise. Journalof Service Industry Management, v. 9, p. 7-23, 1998.

BAPTISTA, P. P. Lealdade do Consumidor e os seus Antecedentes: um Estudo Aplicado ao Setor Varejista na Internet. 2005. Tese (Doutorado em Administração) - Programa de Pós-Graduação em Faculdade de Economia, Administração e Contabilidade - USP, São Paulo.

BARCELLOS, P. F. P. Satisfação do cliente e desempenho empresarial. Apostila para o curso de Mestrado em Administração.Porto Alegre, Universidade Federal do Rio Grande do Sul, 2002. BERRY, L. Retailers with a future. Marketing Management, v. 5, p. 39-46, Spring, 1995.

BERRY, L. L.; PARASURAMAN, A. Serviços de marketing. Rio de Janeiro: Maltese, 1991.

BITNER, Mary Jo. It's all about promises. Journal of the Academy of Marketing Science, v. 4, n. 23, p. 246-251, 1995.

BOLTON, R. N.; DREW, J. H. A Multistage Model of Customers Assessments of Service Quality and Value. Journal of Consumer Research, v. 17, n. 25, p. 375-384, 1991.

BREI, V. A. Antecedentes e conseqüências da confiança do consumidor final em trocas relacionais com empresas de serviço: um estudo com o usuário de Internet banking no Brasil. Porto 2001. Dissertação (Mestrado em Administração) Programa de Pós-Graduação em Administração. Escola de Administração, UFRS, Porto Alegre, 2001.

BREI, V. A.; ROSSI, C. A. V. Confiança, valor percebido e lealdade em trocas relacionais de serviço: um estudo com usuários de Internet Banking no Brasil. Anais Eletrônicos XXVI ENANPAD, 2002.

CARDOZO, R. N. Na Experimental study of consumer effort, expectation and satisfaction. Journal of marketing Research, v. 2, p. 244-249, 1965. 
CARMAN, James M. Consumer Perceptions of Service Quality: an Assessment of the SERVIQUAL dimensions. Journal of Retailing, v. 66, p. 33-35, 1990.

CHAUDHURI, A.; HOLBROOK, M. The Chain of Effects from Brand Trust and Brand Affect to Brand Performance: the Role of Brand Loyaty. Journal of Marketing, v. 55, p. 81-93, 2001.

COSTA FILHO, B. A. Modelo de Influências na doação de inovação: Um estudo para Internet banking, 2002. Tese (Doutorado em administração) Programa de Pós-Graduação em Faculdade de Economia, Administração e Contabilidade - USP, São Paulo, 2002.

COSTA, F. C. X; LARAN, J. A. Influências ambientais e compra por impulso: um estudo em lojas virtuais e físicas. In: Anais eletrônico do $\mathbf{2 7}^{\circ}$ Encontro Anual da ANPAD, Atibaia, Marketing, 2003.

COSTA, F. C. X. Relacionamento entre influências ambientais e o comportamento de compra por impulso: um estudo em lojas físicas e virtuais. 2003. Tese (Doutorado em Administração). Programa de Pós-Graduação em Faculdade de Economia, Administração e Contabilidade - USP, São Paulo, 2003.

DEGERATU, A. M.; RANGASWAMY, A; WU, J. Consumer Choice Behavior in Online and Traditional Supermarkets: The Effects of Brand Name, Price, and Other Search Attributes. International Journal of Research in Marketing, v. 17, p. $55-78,2000$.

DHOLAKIA, U.; BAGOZZI, R. P. Consumer Behavior in Digital Environments.Working Paper, 1999.

DICK, A.; BASU, K. Customer loyalty: toward an integrated conceptual framework. Journal of the Academy of Marketing Science, v. 22, n. 2, p. 99-113, 1994.

DWYER, F. R.; SCHURR, P. H.; OH, S. Developing buyer-seller relationships. Journal of Marketing. v. 2, n. 51, p. 11-27, 1987.

ENGEL, J. F; BLACKWELL, R. D; MINIARD, P. W. Comportamento do consumidor. Rio de Janeiro: LTC, 2000.

FORNELL, C. National and corporate customer satisfaction indexes: a presentation at the world quality day. Amsterdam: World Trade Center, 1991. 
FORNELL, C. et al. The american customer satisfaction index: nature, purpose and findings. Journal of Marketing, New York, v. 60, p. 7-18, 1996.

GARBARINO, E; JOHNSON, M. S.; The different roles of satisfaction, trust and commitment on customer relationships. Journal of Marketing, v. 63, p. 7087, 1999.

GANESAN, S. Determinants of long-term orientation in buyer-seller relationships, Journal of Marketing, v. 2, n. 59, p 1-19, 1994.

GONÇALVES FILHO, C. et al. Comércio eletrônico na Internet: uma pesquisa exploratória no mercado consumidor. In: Anais eletrônico do $2^{\circ}$ Encontro Anual da ANPAD, Foz do Iguaçu, Marketing, 1998.

GRÖNROOS, Cristian. Marketing, Gerenciamento e Serviços: a competição por serviços na hora da verdade. Rio de Janeiro, Campos, 1995.

HAIR Jr. et al. Análise multivariada de dados. Porto Alegre: Bookman, 2005.

HERNANDEZ, J. M. C. Entendendo melhor o processo de decisão de compra na internet: uma análise sobre o papel da confiança em diferentes situações de risco. In: Anais eletrônico do $2^{\circ}$ Encontro Anual da ANPAD, Salvador: Marketing, 2002.

HERNANDEZ, J. M. C. Porque algumas pessoas compram mais que outras pela internet: o papel do conhecimento e do risco percebido. In: Anais eletrônico do $2^{\circ}$ Encontro Anual da ANPAD, Atibaia: Marketing, 2003.

HOFFMAN, D. L.; NOVAK, T. P. A new marketing paradigm for electronic commerce. The information Society Issue on Electronic Commerce. v. 13, p. 43-54, 1996.

JOHNSON, M. D.; FORNELL, C. A framework for comparing customer satisfaction across individuals and product categories. Journal of Economic Psychology, v. 12, n. 2, p. 267-286, 1991.

KOTLER, P. Administração de marketing: a edição do novo milênio. São Paulo: Prentice Hall, 2000. 
LAGES, N. S; BRASIL V. S. Mensurando a Experiência do Consumidor em Ambientes Online: avaliação da escala proposta por Novak. Hoffman e Yung (2000). Anais do $\mathbf{2 7}^{\circ}$ ENANPAD, Rio de Janeiro, 2003.

MARCHETTI, R; PRADO, P. H. M. Um tour pelas medidas de satisfação do consumidor. Revista de Administração de Empresa, v. 41, n. 4, p. 56-67, 2001.

MATTAR, F. N. Pesquisa de marketing. São Paulo: Atlas, 1996.

MCKNIGHT, D. H. et al. Developing and Validating Trust Measures for eCommerce: An Integrative Typology. Information Systems Research. v. 13, p. 334-359, 2002.

NEZZE, M. Fidelização de cliente bancário: o marketing de relacionamento como base na estratégia de lealdade. 2002. Dissertação (Mestrado em Engenharia de Produção) Florianópolis, UFSC, 2002.

NOOTEBOOM, B.; BERGER, H.; NOORDERHAVEN, N. G. Effects of trust and governance on relation al risk. Academy of Management Journal. v. 40, n. 2, p. 308-338, 1997.

OLIVER, R. L. A cognitive model of antecedents and consequences of satisfaction decisions. Journal of Marketing Research. v. 17, p. 460-469, 1980.

. Measurement and evaluation of satisfaction processes in retail setting. Journal of retailing, v. 57, p. 25-48, 1981.

Satisfaction: a behavioral perpective on the consumer. Boston: Irwin McGraw-Hill, 1997.

1999.

Whence consumer loyalty. Journal of Marketing. v. 63, p. 33-44,

OLIVER, R. L.; DESARBO, W. S. Response determinants in satisfaction judgements. Journal of Consumer Research. v. 14, p. 495-507, 1988.

PARASURAMAN, A.; ZEITHAML, V. A.; BERRY, L. L. A conceptual model of service quality and its implications for future research. Journalof Marketing. v. 49, p. 41-50, 1985. 
PRADO, P. H. M. Integração da Qualidade Percebida, Resposta Afetiva e Satisfação. No Processo de Compra-Consumo de serviços. Anais de Marketing do 26$^{\circ}$ Encontro Anual da ANPAD, Salvador, 2002.

PRADO, P. H. M. A avaliação do relacionamento sob ótica do cliente: um estudo em bancos de varejo. 2004 Tese (Doutorado). EAESP-FGV, São Paulo.

REICHHELD, F. O valor da fidelidade, HSM Management, São Paulo, v. 4, n. 21, p. 6-10, 2000.

REICHHELD, F.; SCHEFTER, P. E-Loyalty: your secret weapon on the web. Harvard Business Review, v. 7, p. 105-113, 2000.

RICHARDSON, R. J. Pesquisa Social: métodos e técnicas. São Paulo, Atlas, 1989.

ROSA, F. Canais de atendimento eletrônico e satisfação, retenção e rentabilidade de clientes em bancos. 2001. Tese (Doutorado): FEA-USP, São Paulo, 2001.

ROSA, F. KAMAKURA, W. A. Canais de atendimento eletrônico e satisfação, retenção e rentabilidade de clientes de bancos: um estudo em nível de indivíduo. In: Anais eletrônicos do $2^{\circ}$ Encontro Nacional da ANPAD. Salvador: Marketing, 2002.

ROSA, F. MAZZON, J. A. Satisfação, retenção e rentabilidade de clientes: um estudo, em nível de indivíduo, utilizando-se modelagem de equações estruturais. $1^{\circ}$ Simpósio Nacional de Probabilidade e Estatística. Águas de Lindóia, 2002.

ROSSI, C. A. V.; SANTOS, C. P. O impacto do gerenciamento de reclamações na confiança e na lealdade do consumidor. Revista de Administração Contemporânea, v. 6, p. 49-73, 2002.

ROSSI, C. A. V; SLONGO, L. A. Pesquisa de satisfação de clientes: o estadoda-arte e proposição de um método brasileiro. Anais do XXI ENANPAD/ Marketing, 1997.

ROTTER, J. B. A new scale for the measurement of interpersonal trust. Journal of Personality. v. 35, p. 651-665, 1967. 
ROUSSEAU, F. M. et al. Not so different after all: a cross-discipline view of trust. The Academy of Management Review, v. 23, p. 393-404, 1998.

SANTOS, C. P. Impacto do gerenciamento de reclamações na confiança e lealdade do consumidor, no contexto de trocas relacionais. Anais XXIV ENANPAD, Campinas, 2000.

SCHIFFMAN, L. G; KANUK, L. L. Comportamento do consumidor. 6. ed. Rio de Janeiro: LTC, 2000.

SOLOMON, M. R. O comportamento do consumidor: comprando, possuindo e sendo. Porto Alegre: Bookman, 2002.

TROSTER, Roberto Luis. Introdução à economia. São Paulo, Makron Books, 1999.

URBAN, G. L.; WEINBERG, B. D; HANSER, J. R. Premarket forecasting of really new products. Journal of Marketing, v. 60, p. 47-60, 2000.

TSE, D. K.; WILTON, P. C. Models of consumer satisfaction formation: an extension. Journalof Marketing Research, v. 25, p. 204-212, 1988.

VIEIRA, B. L. A; VIANA, D. A; ECHEVESTE, S. S. Comércio eletrônico via Internet: uma abordagem exploratória. In: Anais eletrônico do $2^{\circ}$ Encontro Anual da ANPAD. Foz do Iguaçu: Marketing, 1998. 